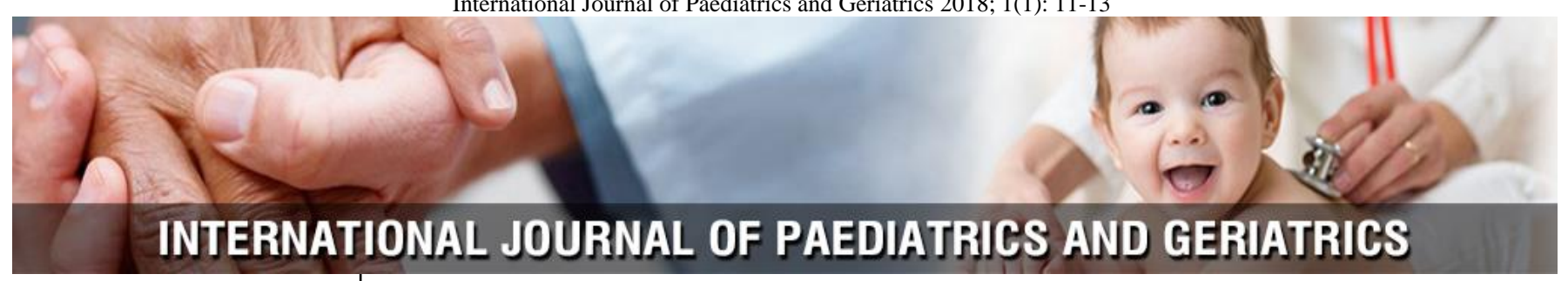

P-ISSN: 2664-3685

E-ISSN: $2664-3693$

www.paediatricjournal.com

IJPG 2018; 1(1): 11-13

Received: 12-11-2017

Accepted: 14-12-2017

Dr. Karthik Aggarwal

Department of Paediatrics, Pushpanjali Hospital,

Haryana, India

\section{Assessment of height and weight pattern in children age ranged 6-12 years of age}

\section{Dr. Karthik Aggarwal}

DOI: $\underline{\text { https://doi.org/10.33545/26643685.2018.v1.i1a.5 }}$

\begin{abstract}
Background: Malnutrition on the other hand causes a lot of morbidities, growth faltering, developmental retardation and significant mortality. The present study was conducted to assess fat pattern in children.

Materials \& Methods: The present study was conducted on 560 children of age ranged 6-12 years of both genders. A semi-structured questionnaire was developed which included some baseline information of the parents and the children in regard to nutrition. Height was measured in $\mathrm{cm}$ and weight was recorded in $\mathrm{kg}$. BMI was recorded as weight/ height ${ }^{2}$.

Results: Out of 560, males were 300 and females were 260. BMI at age 6 was 14.20, at 7 was $14.32 \mathrm{~m}$ at 8 was 14.56 , at 9 was 15.98 , at 10 was 16.28 , at 11 was 17.47 and at 12 was 18.93 . The difference of BMI between different age group was significant $(P<0.05)$.

Conclusion: Authors found that with advancing age, there was increase in BMI of children.
\end{abstract}

Keywords: BMI, Height, Weight

\section{Introduction}

Body composition is a valuable indicator for assessing the adiposity of an individual. The amount of body fat differs with age, sex, genetic, environmental and socio-economic conditions and is very useful for assessing the health and nutritional status of a community ${ }^{[1]}$. Weight and height measurement of children and adults-or weight, length and head circumference measurement of younger children-should be performed on a regular basis as part of providing good clinical care ${ }^{[2]}$. For example, it is necessary to measure weight, height and head circumference in order to monitor children's growth. It is also necessary to measure weight and height (or length) to determine weight status in children and adults [3]. Anthropometric measurements are still widely used to assess the body composition in many fields and epidemiological investigations ${ }^{[4]}$.

Malnutrition on the other hand causes a lot of morbidities, growth faltering, developmental retardation and significant mortality. Growth is determined by biological determinants including sex, birth weight and genetic constitution. Socioeconomic and environmental factors seem to produce their effects by the presence of nutritional deficiencies, parasitic infections and psychosocial illnesses. The two most important factors that contribute to a sudden increase in the incidence of obesity are changes in dietary practices and urbanization ${ }^{[5]}$. The present study was conducted to assess fat pattern in children.

\section{Materials \& Methods}

The present study was conducted in the department of Pediatrics. It comprised of 560 children of age ranged 6-12 years of both genders. The permission for the study was achieved from respective school.

Data such as name, age, gender etc. was recorded in case record file. A semi-structured questionnaire was developed which included some baseline information of the parents and the children in regard to nutrition. Height was measured in $\mathrm{cm}$ and weight was recorded in $\mathrm{kg}$. BMI was recorded as weight/ height ${ }^{2}$. Results were tabulated and subjected to statistical analysis. $\mathrm{P}$ value less than 0.05 was considered significant.
Corresponding Author: Dr. Karthik Aggarwal Department of Paediatrics, Pushpanjali Hospital, Haryana, India 


\section{Results}

Table I: Distribution of patients

\begin{tabular}{|c|c|c|}
\hline \multicolumn{3}{|c|}{ Total- 560 } \\
\hline Gender & Males & Females \\
\hline Number & 300 & 260 \\
\hline
\end{tabular}

Table I shows that out of 560, males were 300 and females were 260 .

Table 2: Particulars of children

\begin{tabular}{|c|c|c|c|c|}
\hline $\begin{array}{l}\text { Age group } \\
\text { (Years) }\end{array}$ & $\begin{array}{c}\text { Height } \\
\text { (cm) }\end{array}$ & $\begin{array}{c}\text { Weight } \\
\text { (Kg) }\end{array}$ & $\begin{array}{c}\text { BMI } \\
\left(\mathrm{Kg} / \mathrm{m}^{2}\right)\end{array}$ & $\begin{array}{c}\mathbf{P} \\
\text { value }\end{array}$ \\
\hline 6 & 117.2 & 19.20 & 14.20 & \multirow{7}{*}{0.01} \\
\hline 7 & 120.1 & 21.42 & 14.32 & \\
\hline 8 & 123.6 & 23.5 & 14.56 & \\
\hline 9 & 125.7 & 24.1 & 15.98 & \\
\hline 10 & 128.2 & 24.9 & 16.28 & \\
\hline 11 & 130.6 & 25.8 & 17.47 & \\
\hline 12 & 132.5 & 26.6 & 18.93 & \\
\hline
\end{tabular}

Table II, graph I shows that BMI at age 6 was 14.20 , at 7 was $14.32, \mathrm{~m}$ at 8 was 14.56 , at 9 was 15.98 , at 10 was 16.28 , at 11 was 17.47 and at 12 was 18.93 . The difference of BMI between different age group was significant $(\mathrm{P}<$ $0.05)$.

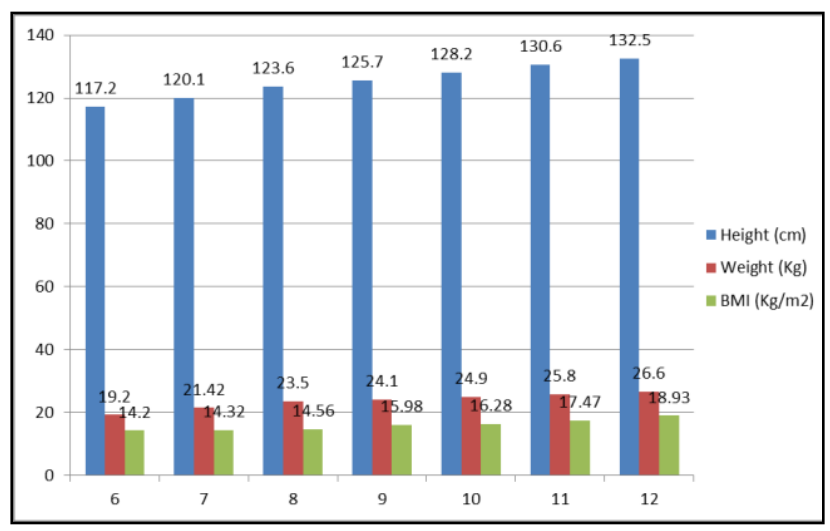

Graph I: Particulars of children

\section{Discussion}

The two most important factors that contribute to a sudden increase in the incidence of obesity are changes in dietary practices and urbanization. Apart from dietary changes, sedentary lifestyles and lack of adequate physical activity have also been observed, which in turn have contributed to the increased incidence of obesity.

Touitou et al. ${ }^{[6]}$ found that the mean height, weight and BMI of the children of both government and private school were seen to increase with age. The mean height and mean weight of the children of private school was the found to be significantly higher $(\mathrm{p}<0.05)$ than that of government school. The prevalence of underweight was found to be higher in the children of the government school than the private school, whereas the prevalence of overweight and obesity was found to be higher in the children of the private school than the government.

In present study, out of 560, males were 300 and females were 260. BMI at age 6 was 14.20 , at 7 was 14.32 , at 8 was 14.56 , at 9 was 15.98 , at 10 was 16.28 , at 11 was 17.47 and at 12 was 18.93 . The difference of BMI between different age group was significant $(\mathrm{P}<0.05)$.

By using the CDC 2000 growth standards, more children were likely to be regarded as underweight and many children with overweight or obesity were likely to be regarded as normal as compared to growth standards compiled by Mishra et al., $2001{ }^{[7]}$. The differences noticed in the growth parameters between government and private school children might be due to the socioeconomic disparity between the two.

The distribution and amount of body fat (e.g., FM) and composition of muscle mass (e.g., lean body mass or FFM) are important to understand the health outcomes in body composition assessment in infants and children. Studies have reported marked ethnic differences in the relationship of visceral and peripheral adiposity. But the differences in distribution of fat are evident during early childhood with differences in total body adiposity onset before puberty. Such differences in body fat distribution are mediated by the hormonal fluctuations. Several studies have authenticated different skinfold equations with alternate methods of estimation and recommended the use of the equations of Slaughter et al. ${ }^{[8]}$. in 1988 for the evaluation of body fat among pre-pubertal children.

Malina et al. ${ }^{\text {[9] }}$ found that correlation study suggests that increased PBF and FFM are accompanied by an increase in anthropometric measurements between the two populations. Significant relationship between BMI and PBF, and BMI and FFM, indicate that changes in BMI represent changes in PBF and FFM. Again, the significant correlation between PBF and FFM highlights that the developing pattern of PBF and FFM are similar in tribal and non-tribal populations.

\section{Conclusion}

Authors found that with advancing age, there was increase in BMI of children.

\section{References}

1. Debnath S, Mondal N, Sen J. Socio-economic and demographic correlates of stunting and thinness among rural school-going children (aged 5-12 years) of North Bengal, Eastern India. J Life Sci. 2018; 10:29-46.

2. Eveleth PB, Tanner JM.Worldwide variation in human growth, $2^{\text {nd }}$ ed. Cambridge University Press: Cambridge; 1990.

3. Reddon H, Guéant JL, Meyre D. The importance of geneenvironment interactions in human obesity. Clin Sci. 2016; 130: 1571-97.

4. Sharma J, Singh KN, Mondal N. Effects of certain socio-economic and demographic variables on the prevalence of stunting among adolescent girls of Assam. In: Sengupta S, editor. Contemporary Anthropological Research in Eastern and North Eastern India. New Delhi: Gyan Publishing House, 2017, 183200.

5. Sharma J, Mondal N. Physical growth and body composition assessment among rural adolescent girls (10-16 years) of Karbi Anglong, Assam, Northeast India. J Life Sci. 2018; 10:16-28.

6. Touitou Y, Portaluppi F, Smolensky MH, Rensing L. Ethical principles and standards for the conduct of human and animal biological rhythm research. Chronobiol Int. 2004; 21:161-70.

7. Mishra D, Singh HP. Kuppuswami's socio-economic status scale-A revision. Indian J Pediatr. 2003; 70:273- 
4.

8. Slaughter, Uijaszek SA, Kerr DA. Anthropometric measurement error and the assessment of nutritional status. Br J Nutr. 1999; 82:165-77.

9. Malina RM, Brown KH, Zavaleta AN. Relative lower extremity length in Mexican American and in American black and white youth. Am J Phys Anthropol. 1987; 72:84-94. 